Article

\title{
Electromagnetic Susceptibility of Battery Management Systems' ICs for Electric Vehicles: Experimental Study
}

\author{
Orazio Aiello (D) \\ Department of Electronics and Telecommunications, Politecnico di Torino, Corso Duca degli Abruzzi 24, \\ I-10129 Torino, Italy; orazio.aiello@polito.it
}

Received: 20 January 2020; Accepted: 13 March 2020; Published: 19 March 2020

\begin{abstract}
The paper deals with the susceptibility to electromagnetic interference (EMI) of battery management systems (BMSs) for Li-ion and lithium-polymer (LiPo) battery packs employed in emerging electric and hybrid electric vehicles. A specific test board was developed to experimentally assess the EMI susceptibility of a BMS front-end integrated circuit by direct power injection (DPI) and radiated susceptibility measurements in an anechoic chamber. Experimental results are discussed in reference to the different setup, highlighting the related EMI-induced failure mechanisms observed during the tests.
\end{abstract}

Keywords: battery management system (BMS); Li-ion battery pack; electric vehicles (EVs); hybrid electric vehicles (HEVs); IC-level EMC; susceptibility to electromagnetic interference (EMI); direct power injection (DPI); anechoic chamber

\section{Introduction}

A greater and greater increase in the amount of electronic devices is expected in new vehicles to make cars capable of running self-diagnostics and interacting with the surrounding environment. On-board electronics systems for implementing safety features to reduce the number of accidents and fatalities on the roads have to properly operate in any operating conditions [1]. Smart power integrated circuits (ICs) employed in automotive front-end electronics have stringent requirements in terms of accuracy, even in an electromagnetically polluted environment, where relevant conducted and radiated interference are generated by the electric powertrain, by on-vehicle electronics and by mobile phones and/or other information and communication equipment carried by the driver and by the passengers in the cockpit [1]. Therefore, the susceptibility to electromagnetic interference (EMI) of smart power electronics and its on-board monitoring and control functions (i.e., thermal shutdown, current sensors and overvoltage protection) has to be considered. This to prevent malfunctions and guarantee the correct/expected functioning of the electronic system in any operating conditions [1-6].

Critical safety EMI-induced failures could be also a major threat to the safety in emerging electric and hybrid electric (EV/HEV) vehicles powered by batteries [7]. A battery management system (BMS) IC manages the state of charge of the battery pack, protecting it from operating outside its safe operating conditions [8-13]. Electromagnetic interference can be easily picked up by the long wires that connect BMS front-end ICs to each other, to the BMS control unit, to the terminals of the electrochemical cells and to the temperature sensors, which are spatially distributed over the whole battery pack module [14], and can easily impair the operation of data acquisition circuits [15-18].

Battery packs based on the most advanced lithium-ion (Li-ion) and lithium-polymer (LiPo) electrochemical technologies are nowadays the only viable options to address the challenging demands in terms of the electric energy storage and deliverable power per unit mass of electric vehicles 
(EVs) and hybrid electric vehicles (HEVs) [19-22]. Unfortunately, unlike lead-acid batteries and other more conventional electrochemical accumulators, Li-ion and LiPo cells can be permanently damaged and can also originate life-threatening hazards such as fires and explosions in the event of overdischarging, overcharging and/or overtemperature operation [21-23]. An electronic battery management system (BMS), which quickly detects the onset of dangerous conditions and takes the appropriate countermeasures to avoid hazards, is therefore necessary to safely operate Li-ion and LiPo cells in vehicles [21-23]. A BMS, which is schematically depicted in Figure 1, typically includes several front-end modules that acquire critical cell information, such as terminal voltages and temperatures, and a digital control unit that runs specific control and management algorithms.

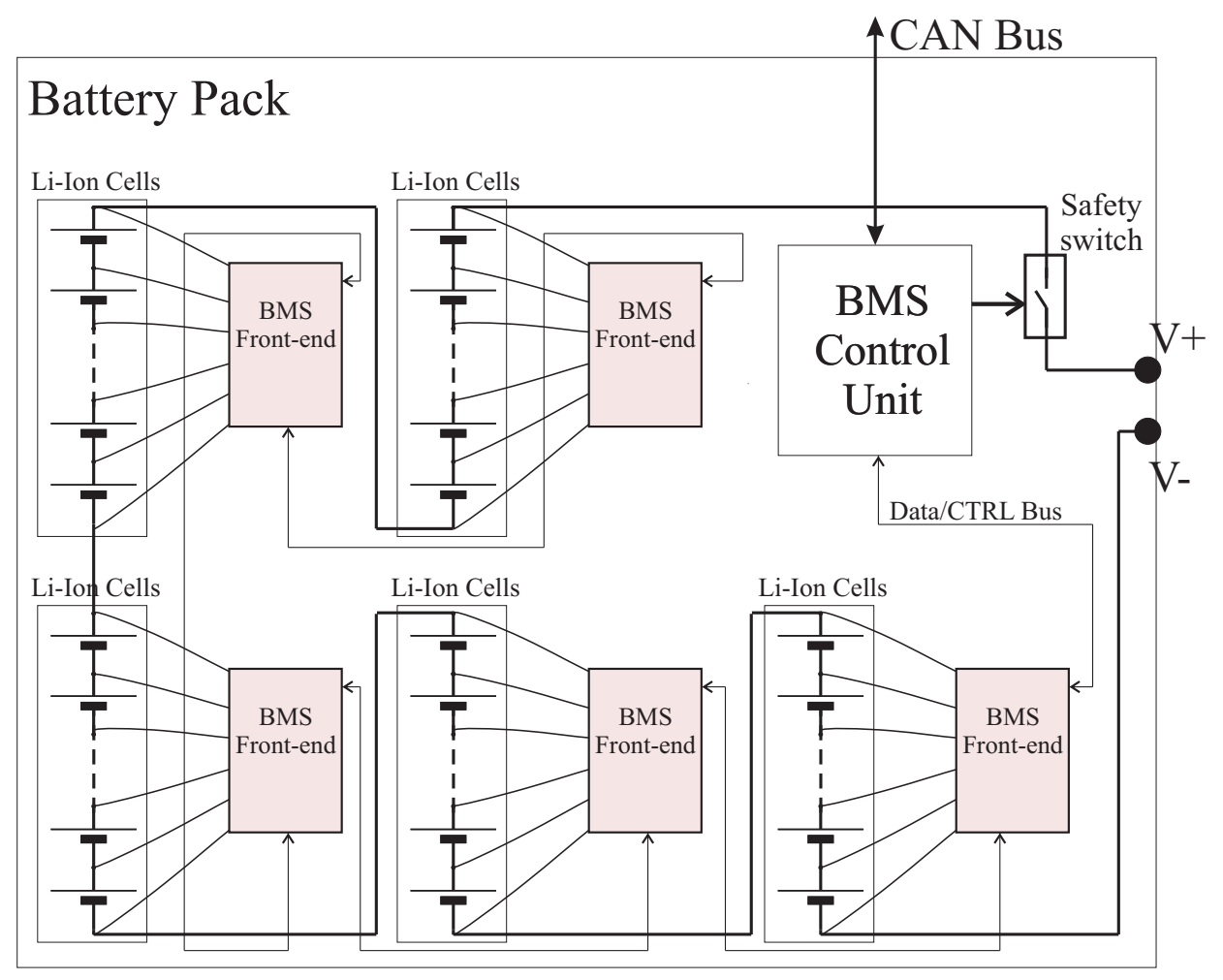

Figure 1. Architecture of a battery management system (BMS) for EV/HEV applications.

The typical BMS application scenario in Figure 1 and the EMI susceptibility issues of BMS systems for electric vehicles are addressed in this paper on the basis of the results of direct power injection (DPI) tests (IEC-62132-4 standard [24,25]) and radiated susceptibility tests (ISO11452-2 standard [26]) on a commercial smart power IC, widely employed as a BMS front-end in EV/HEV applications. In particular, the specific susceptibility level of the main IC pins and their different EMI-induced failure mechanisms were observed. The effectiveness of filtering techniques that can be adopted to enhance the immunity to EMI of a BMS, is also discussed.

The paper is organized as follows: in Section 2, the BMS IC is presented, and the printed circuit board (PCB) developed to perform EMC tests is introduced; in Section 3 the test bench and the test procedure adopted for DPI measurements are described. DPI test results are presented in Section 4 and discussed in Section 5. The results of radiated susceptibility measurements are presented in Section 6 and compared to the DPI tests in Section 7, and finally, in Section 8, some concluding remarks are drawn. 


\section{The BMS Front-End for the Tests}

In order to investigate the susceptibility to EMI of a BMS for electric vehicles and perform the related conducted (DPI) and radiated (in anechoic chamber) tests, a PCB was specifically designed, and it is described in this Section.

\subsection{BMS Front-End IC Structure and Operation}

The simplified block diagram of the BMS front-end IC, which is considered in what follows as the device under test (DUT), is reported in the pink box of Figure 2. Such an IC is designed to monitor the terminal voltages of up to twelve series-connected electrochemical cells using a 12-bit analog-to-digital converter (ADC). To that end, the IC includes 12 cell input pins, internally connected to the ADC's differential input by a 12-channel, isolated, high-voltage analog multiplexer to measure the (differential) voltages across each of twelve series-connected cells, whose common-mode voltage can be up to $50 \mathrm{~V}$ with respect to the IC reference.

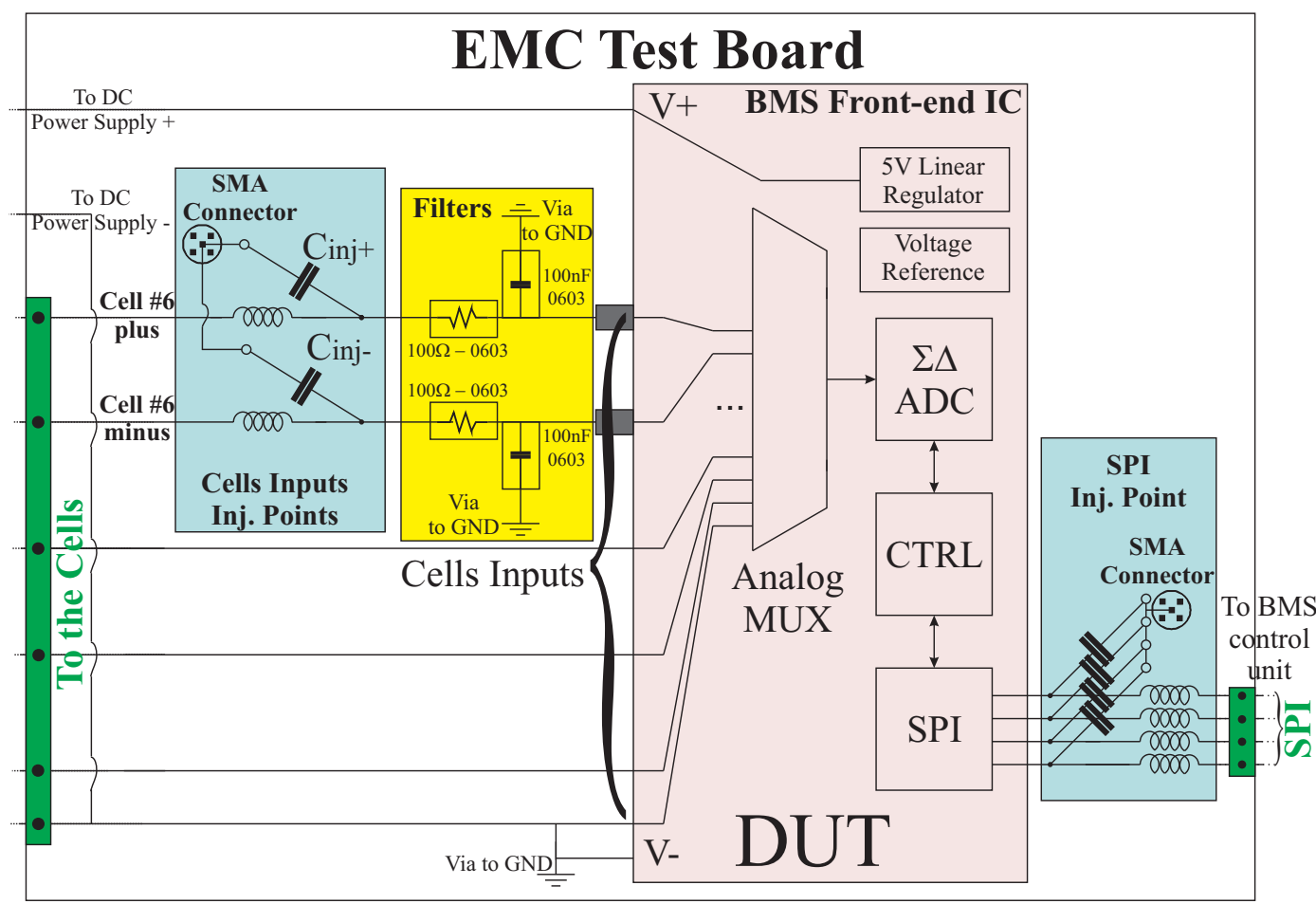

Figure 2. Simplified schematic diagram of the BMS integrated circuit (IC) direct power injection (DPI) test board.

The same IC can be also exploited for cell temperature measurements by using external negative temperature coefficient (NTC) sensors and including power drivers suitable for performing passive Li-ion cell voltage equalization. These functions have not been considered the susceptibility assessment and will not be mentioned hereafter.

The IC is designed to be operated by an external BMS control unit via a serial peripheral interface (SPI), through which acquired data can also be retrieved. The same SPI interface can be employed to connect the BMS IC to $N$ similar devices in a daisy chain structure, as shown in Figure 1, so as to monitor up to $12 \mathrm{~N}$ cells, addressing the requirements of high voltage battery packs including 100 or more series-connected cells. The frame of the specific SPI protocol implemented in the DUT includes a packet error code (PEC), by which SPI bus errors can be detected on the basis of the received data.

The IC operates from a DC supply voltage ranging from $10 \mathrm{~V}$ up to $55 \mathrm{~V}$, which can be obtained either from the electrochemical cells to be monitored or from an external isolated DC/DC converter, 
and includes an internal voltage reference for the ADC and a $5 \mathrm{~V}$ linear voltage regulator to supply the low voltage analog and digital circuitry.

\subsection{DPI Test Board}

Firstly, the susceptibility to EMI of the DUT has been tested by the DPI method [24,25]. The dual layer PCB reported in Figure 2 has been designed to inject RF power into the IC pins which are connected to the external wires. These possibly long wires are likely to collect a relevant amount of EMI in a realistic EV/HEV application. Two DPI injection points are established to superimpose an RF power into a couple of cell input pins and into the SPI pins of the IC, as depicted in Figure 2.

The cell input injection point includes an SMA connector and two RF coupling networks (each made up of a $6.8 \mathrm{nF}$ capacitor and a $6 \mu \mathrm{H}$ inductor), designed so as to inject RF power onto the cell input pins connected to the positive and to the negative terminals of cell \#6 in the stack, as depicted in Figure 2. A differential RF injection on a single cell input pin (cell \#6 plus in Figure 2) can be performed by connecting only the injection capacitor $C_{\text {inj }}^{+}$to the signal terminal of the SMA connector. A common-mode injection can be performed by connecting both the injection capacitors $C_{\text {inj }}^{+}$and $C_{\text {inj }}^{-}$ to the SMA signal line.

Figure 2 shows how the cell input injection points include an SMA connector and two RF coupling networks (each made up of a $1 \mathrm{nF}$ CHECK capacitor and a $6 \mu \mathrm{H}$ inductor). Two $R C$ filters with $R=100 \Omega, C=100 \mathrm{nF}$ implemented using $0603 \mathrm{SMD}$ components (sketched in the yellow area) are mounted on the PCB immediately before the IC pins. The SPI injection point includes an SMA connector and four RF coupling networks (each made up of a $1 \mathrm{nF}$ capacitor and a $6 \mu \mathrm{H}$ inductor), designed to perform DPI on all the SPI inputs at the same time, or alternatively, on a single SPI line.

\section{Direct Power Injection Tests}

The failure criteria considered in the DPI tests are stated along with the reasoning in this section.

\subsection{DPI Test Bench}

The PCB in Figure 2 has been employed to perform the DPI method according the setup in Figure 3. The DUT is operated from an external $20 \mathrm{~V}$ power supply and the cell inputs of the DUT are connected to six series-connected commercial nickel metal hydride (NiMH) cells mounted on a separate board and tied to the DUT cell inputs by twisted wires. The current flowing through the cells during the DPI test is monitored by an amper meter, as shown in Figure 3.

The SPI lines of the DUT are connected to an automotive microcontroller evaluation board, which acts as the BMS control unit shown in Figure 1. Such a BMS control unit includes a controller area network (CAN) bus interface that is connected to a personal computer (PC) via a Vector CANCaseXL dongle. The microcontroller on the BMS control unit is programmed so as to forward the data content of the CAN packets with a specific identifier (ID) to the DUT SPI, and to send back to the CAN bus, with a different ID, the data retrieved from the DUT SPI during the same transaction. In this way, the DUT can be fully operated and monitored from the PC via the CAN bus. The CAN bus and the measurement instruments are managed by Matlab. The BMS IC is configured to be initialized, start the $\mathrm{ADC}$ conversion and read the register. 


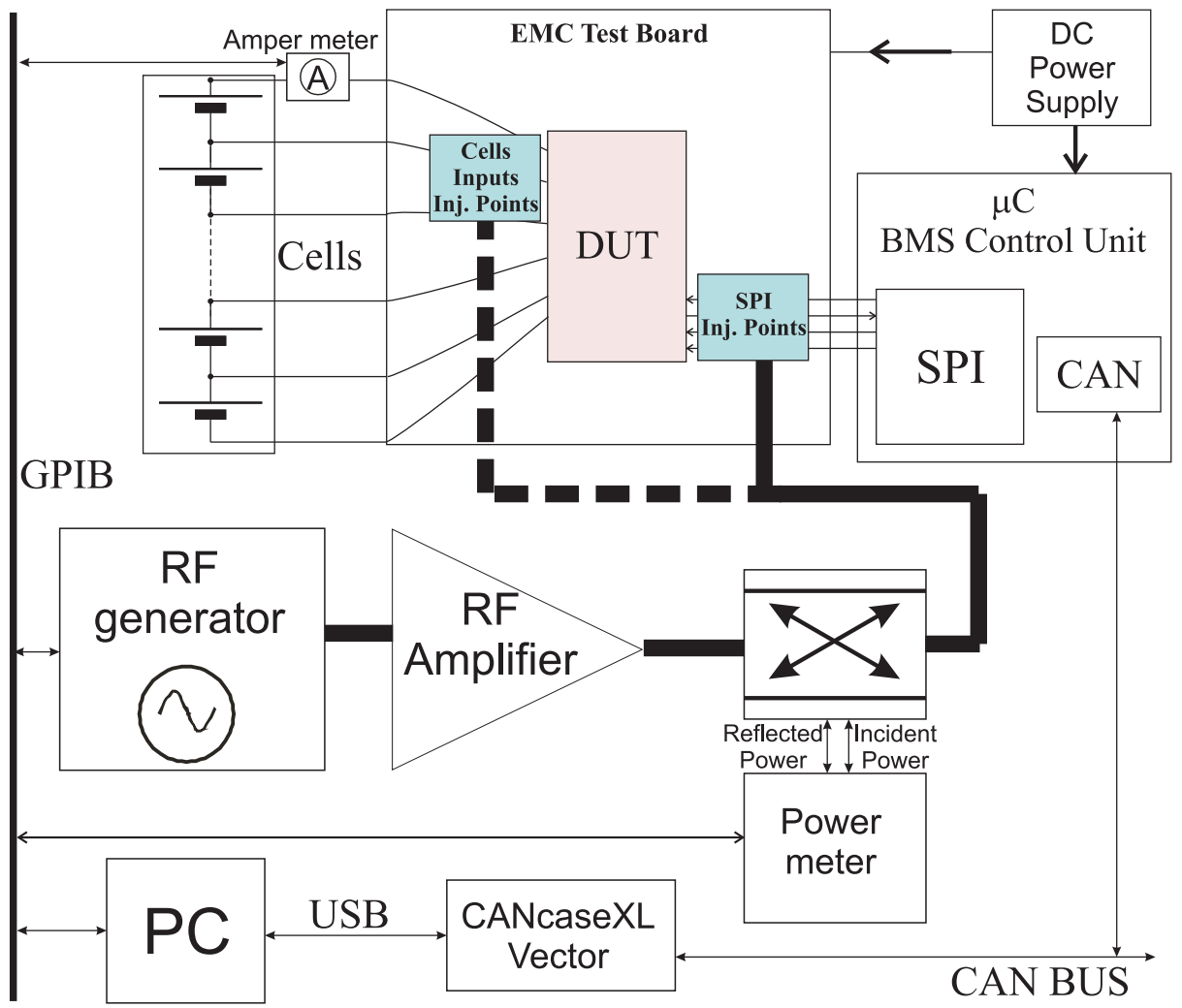

Figure 3. Direct power injection. Experimental test setup.

The continuous wave (CW) RF power injection is performed by means of an RF source connected to a $10 \mathrm{~W}$ RF power amplifier with a $1 \mathrm{MHz}$ to $2 \mathrm{GHz}$ bandwidth. The output of the power amplifier is fed to the injection points of the test board through a $-20 \mathrm{~dB}$ directional coupler, whose forward and reverse coupled ports are connected to an RF power meter so as to monitor the incident and the reflected power. The RF source, the amper meter and the RF power meter are connected to the same PC employed to control the DUT via a general purpose interface bus (GPIB) dongle. Both the CAN bus and the GPIB are fully controlled by the PC in the Matlab environment.

\subsection{DPI Test Procedure}

During DPI tests, the DUT is operated from the PC in Figure 3 so as to periodically acquire the voltages of all the cells in the battery pack. The acquired data are then retrieved from the DUT SPI by the BMS control unit and forwarded to the PC via the CAN bus, together with the corresponding SPI PEC code. The same operations are first performed without injecting RF power (i.e., with the RF source in Figure 3 off) and then while injecting RF power at a given test frequency. The data retrieved from the DUT, with and without EMI injection, are finally compared and an EMI-induced failure is recorded if one of the following conditions occurs:

1. An SPI transmission error is detected (i.e., the received PEC is not consistent with the received data);

2. An EMI-induced offset in the cell voltages acquired with RF injection exceeding an error threshold $V_{\mathrm{T}}$ is detected.

Taking into account of the accuracy level that is required to safely manage Li-ion cells [23], and the declared maximum error of the IC, an error threshold $V_{\mathrm{T}}=10 \mathrm{mV}$ is considered in this paper.

Considering the above failure criteria, DPI tests have been performed for each test frequency in the $1 \mathrm{MHz}$ to $2 \mathrm{GHz}$ bandwidth by increasing the injected RF incident power until a failure is detected. Notice that the IEC 62132-4 frequency bandwidth (1 MHz-1 GHz) has been extended to 
$2 \mathrm{GHz}$ to include the $1.8 \mathrm{GHz}$ frequency, widely employed in wireless communications. The minimum $\mathrm{RF}$ incident power giving rise to the failure is then reported as the DPI immunity level at the test frequency. If no failure is detected at the maximum test incident power $P_{\max }=37 \mathrm{dBm}$, no immunity level indication is reported. The results of DPI tests performed according with the above procedure are presented in the next Section.

\section{DPI Experimental Results}

The DPI immunity tests on the DUT cell inputs and SPI injection points in Figure 2 are reported in this Section. The different failure mechanisms observed are highlighted and the effectiveness of PCB level filtering on cell inputs is discussed.

\subsection{Injection of Cell Inputs}

The EMI robustness of the DUT undergoing DPI on the cell input injection point is considered comparing a differential (DM) excitation and a common-mode (CM) one. Differential (DM) excitation is performed by connecting only the injection capacitor $C_{\text {inj }}^{+}$to the signal terminal of the SMA connector in Figure 2. Common-mode (CM) excitation is performed by connecting both the injection capacitors $C_{\text {inj }}^{+}$and $C_{\text {inj }}^{-}$to the SMA signal line. Both the tests have been repeated without the RC filters in Figure 2 (i.e., using $0 \Omega 0603 \mathrm{SMD}$ resistors and not mounting the filter capacitors) and with the $100 \Omega-100 \mathrm{nF}$ $R C$ filters prescribed by the IC manufacturer.

The respective measurement results are reported in Figure 4. The DPI immunity level of the DUT without filters is very similar for CM and DM injection and it is mostly in the range of 5-15 dBm over the $1 \mathrm{MHz}$ to $1 \mathrm{GHz}$ bandwidth. A very high susceptibility to EMI (immunity level of less than $0 \mathrm{dBm}$ ) can be observed at $16 \mathrm{MHz}$ and harmonic frequencies, which are likely to be related with the internal clock frequency of the sigma-delta converter built-in the BMS IC. As such, EMI-induced failures do not seem to be specifically related to EMI superimposed onto the differential cell voltage to be acquired, but rather to other mechanisms involving the RF voltage between each test pin and the IC reference (ground) voltage.

The presence of $R C$ filters provides a significant immunity enhancement in the $20-600 \mathrm{MHz}$ band (a single failure is experienced at $150 \mathrm{MHz}$ at the $37 \mathrm{dBm}$ test level), whereas their effectiveness is lower above $600 \mathrm{MHz}$. This can be explained by considering that the impedance of the $0603,100 \mathrm{nF}$ capacitor of the filter, dominated above $20 \mathrm{MHz}$ by the parasitic inductance $\mathrm{ESL} \simeq 1 \mathrm{nH}$, in series with the PCB track and via inductance $\left(L_{\text {track }} \simeq 1 \mathrm{nH}\right.$ and $\left.L_{\text {via }} \simeq 1 \mathrm{nH}\right)$, gives rise to a parallel resonance with the input capacitance of the BMS IC ( $C_{\mathrm{IN}} \simeq 15 \mathrm{pF}$ from S-parameters measurements) at a frequency:

$$
f_{0}=\frac{1}{2 \pi \sqrt{\left(\mathrm{ESL}+L_{\text {track }}+L_{\text {via }}\right) C_{\mathrm{IN}}}} \simeq 700 \mathrm{MHz}
$$

Close to this frequency, the actual impedance of the parallel element of the $R C$ filter (capacitor $C$ and parasitics) is very high and its filtering effectiveness is therefore impaired. 


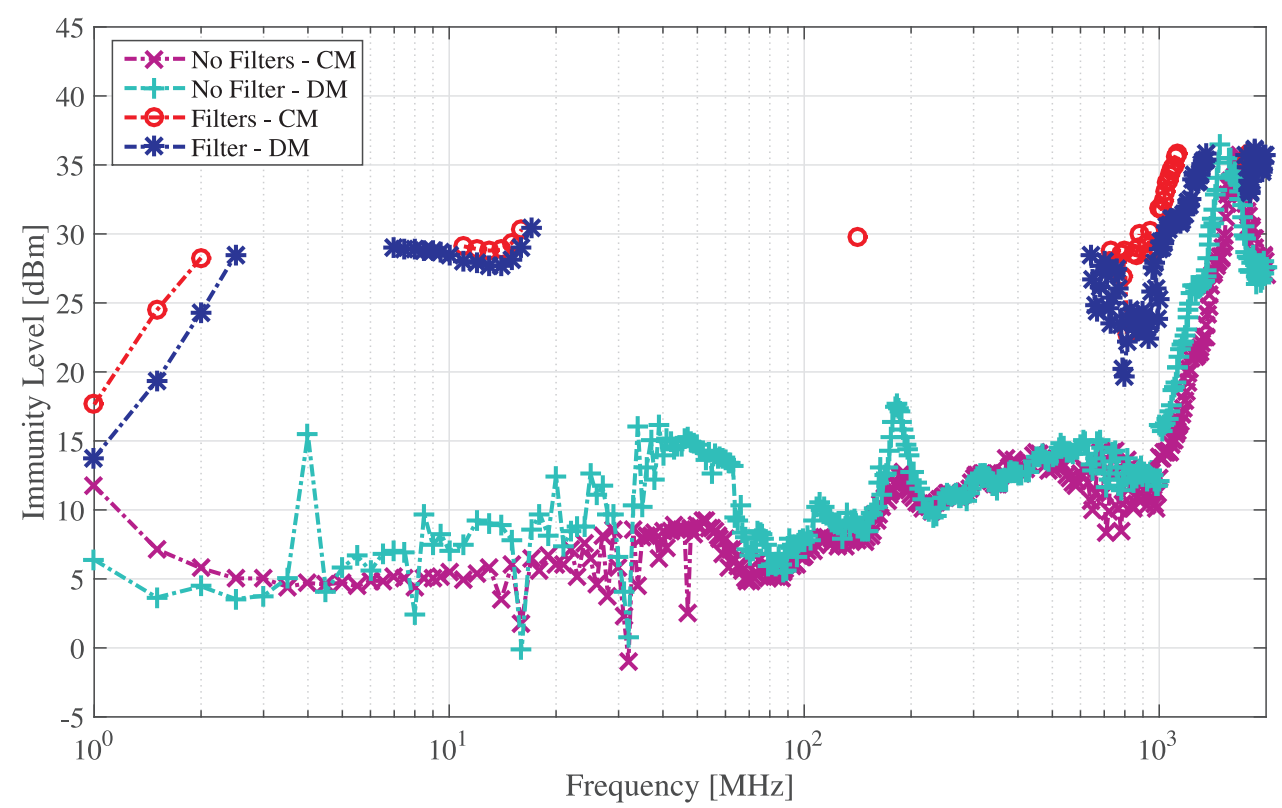

Figure 4. Measured immunity level (expressed in terms of RF incident power) for DPI on the cell input pins: differential (DM) and common-mode (CM) injection, with and without $R C 100 \Omega, 100 \mathrm{nF}$ RC filters in Figure 2.

\subsubsection{Test Port Voltage Estimation}

To gain further insights into the intrinsic susceptibility level of the IC and the effectiveness of the filters, the peak RF voltage at the test board injection port giving rise to the failures reported in Figure 4 has been estimated on the basis of the reflection coefficient $\Gamma$ at the test board injection port, measured by a calibrated vector network analyzer (VNA). Taking into account that the peak RF voltage at the test port $V_{\text {rf }}$ can be expressed in terms of the RF incident power $P_{\text {inc }}$ as

$$
V_{\text {rf }}=|1+\Gamma| \sqrt{2 R_{\mathrm{G}} P_{\text {inc }}},
$$

where $R_{\mathrm{G}}=50 \Omega$ is the reference port resistance, the incident power immunity levels have been translated into the corresponding test port voltages in Figure 5. On this basis, it can noticed that an injected RF voltage with a peak amplitude even lower than $1 \mathrm{~V}$ (lower than 0.5 in the worst case) is sufficient to induce a failure in the BMS IC without filters. Moreover, by comparing the failure levels in Figure 4, expressed in terms of incident power, and the results in Figure 5, expressed in terms of injection port voltage, it can be appreciated that the immunity enhancement brought by the filters in the $800 \mathrm{MHz}$ to $2 \mathrm{GHz}$ range is much lower if expressed in terms of the injection port voltage than in terms of incident power, and both the filtered and the unfiltered ICs undergo a failure for an injected EMI peak amplitude of about $3 \mathrm{~V}$. 


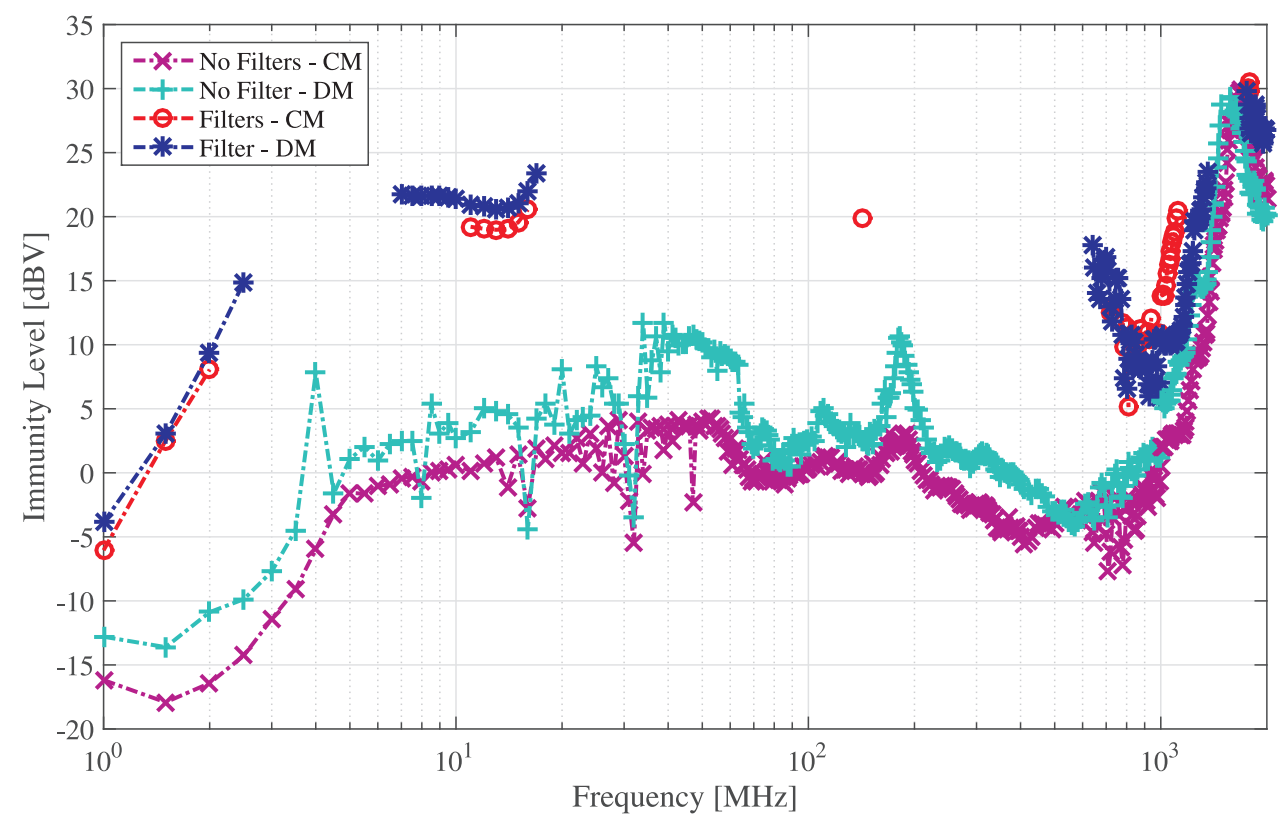

Figure 5. Total RF voltage induced at the DPI injection port corresponding to the DPI immunity levels in Figure 4.

\subsubsection{Failure Mechanisms}

During EMI induced failures reported in Figure 4, no SPI communication failure (inconsistent PEC) was reported when performing DPI injection on the cell inputs. In all cases, in fact, failures events were related to an EMI-induced offset exceeding $10 \mathrm{mV}$ in the cell voltage readings. Such an offset voltage, defined for each cell $i$ as

$$
V_{\mathrm{OFF}, i}=V_{\mathrm{ADC}, i, \mathrm{EMI}}-V_{\mathrm{ADC}, i}
$$

where $V_{\mathrm{ADC}, i, \mathrm{EMI}}$ is the $i$-th cell voltage acquired by the DUT while injecting an RF power corresponding to the immunity level in Figure 4, and $V_{\mathrm{ADC}, i}$ is the voltage of the same cell acquired by the DUT without RF power injection, is plotted for each cell in Figure 6 for the unfiltered IC, and in Figure 7 for the IC including RC filters. In both cases, DM injection is considered.

Figure 6 shows how that failures up to about $300 \mathrm{MHz}$ are related to an EMI-induced offset exceeding $10 \mathrm{mV}$ in the acquired voltage of cell \#6; i.e., on the cell on which DPI is performed. On the contrary, for EMI frequencies above $300 \mathrm{MHz}$, all the acquired cell voltages show a similar offset. Such a behavior can be related to the direct propagation of EMI to the internal ADC and/or to its reference voltage source. 


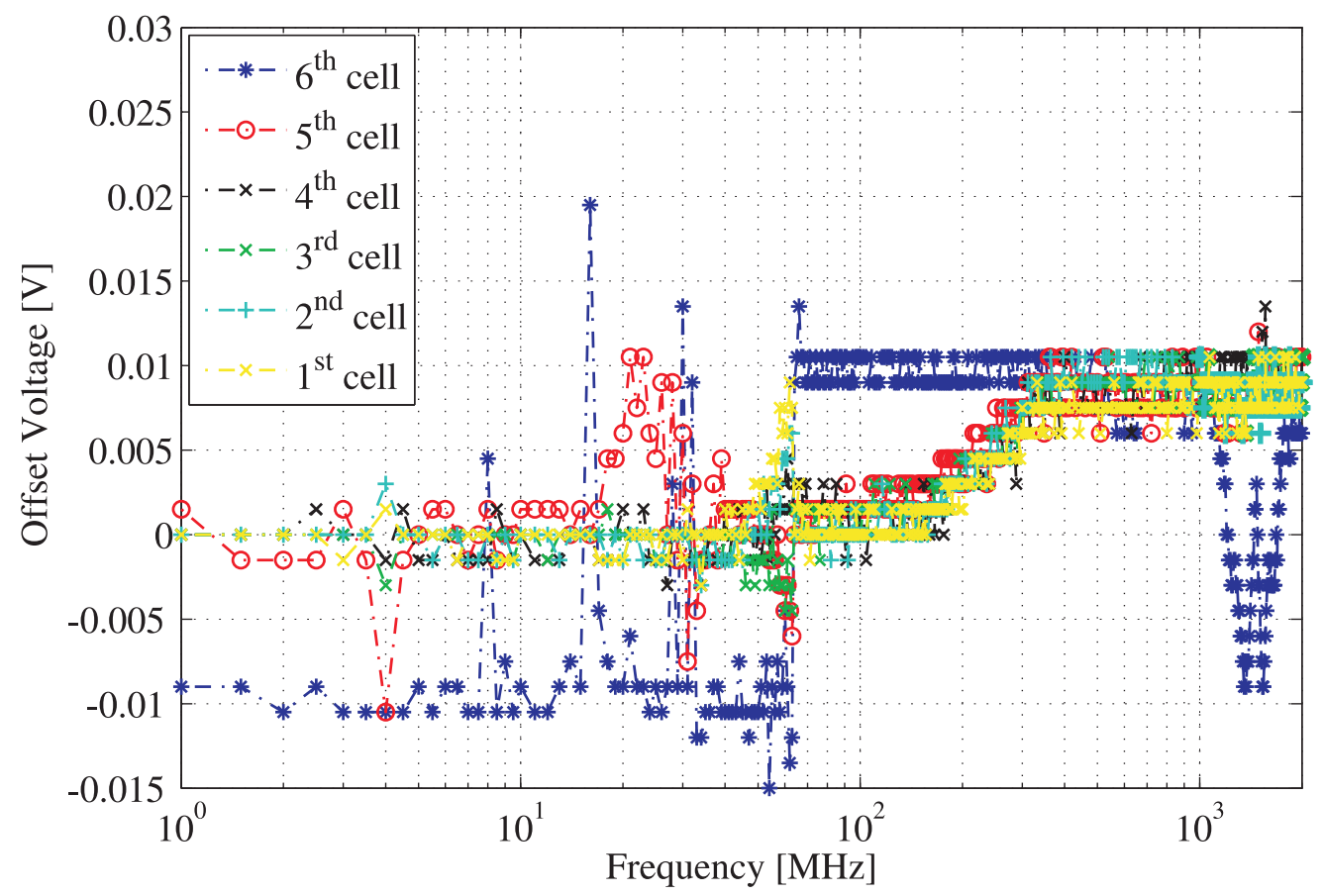

Figure 6. EMI-induced offset in the cell voltage readings obtained in accordance with DPI failure levels of Figure 4 (DM injection performed on the 6th cell positive terminal, without RC filters).

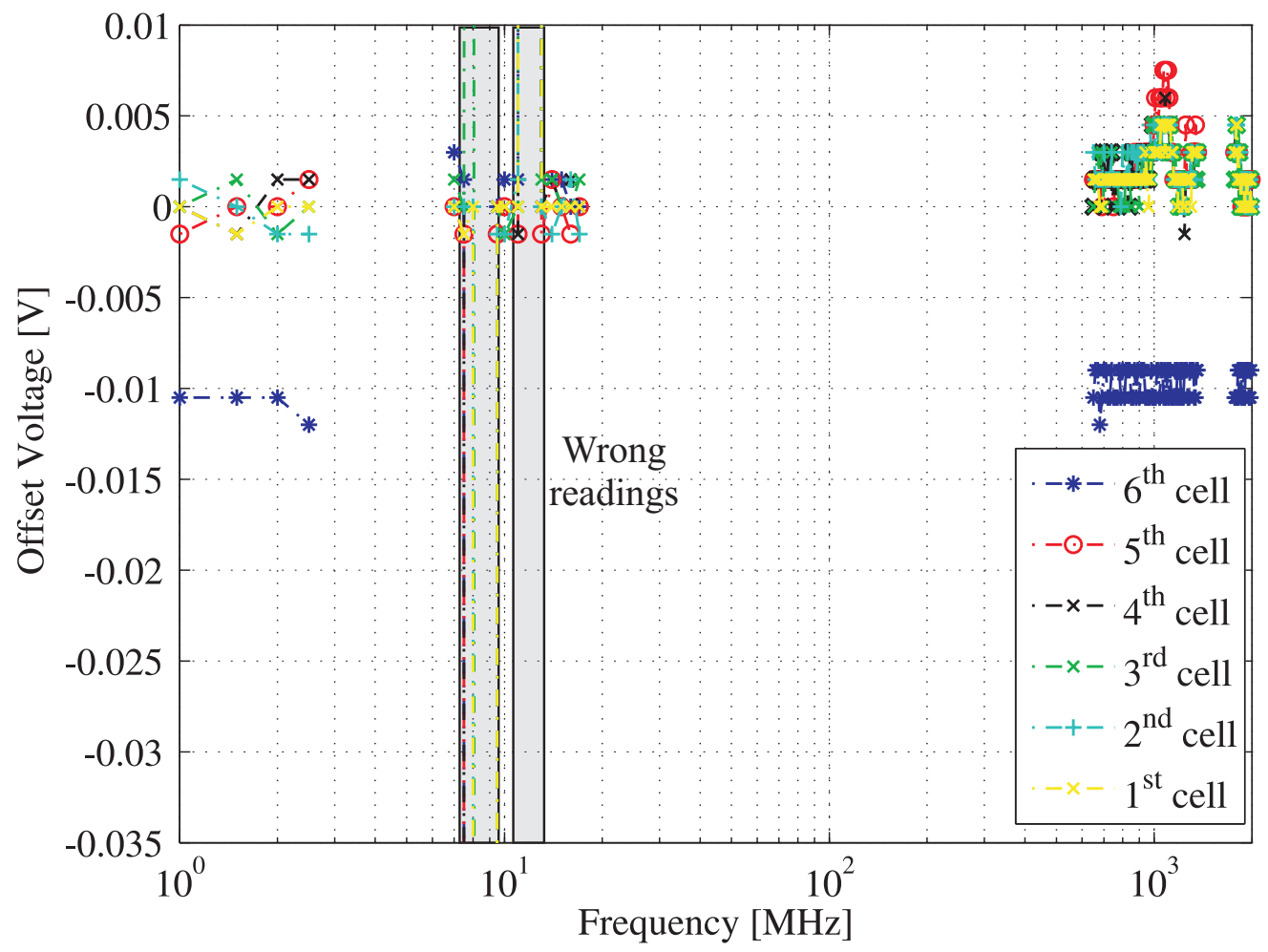

Figure 7. EMI-induced offset in the cell voltage readings obtained in accordance with DPI failures level of Figure 4 (DM injection performed on the 6th cell positive terminal, with RC filters).

Figure 7 shows a different failure mechanism for the filtered device undergoing RF DPI in the 8-12 $\mathrm{MHz}$ band (reported as a wrong reading gray area). In this case, injected EMI gives rise to completely wrong ADC readings, corresponding to the maximum or to the minimum values of the ADC range. 
At lower and higher frequencies the failure mechanisms related to the offset presence are observed. Similar results have been obtained performing CM injection.

Finally, the DC current delivered by the battery pack and measured by the DC amper meter (see Figure 3) in accordance with the DPI failure levels shown in Figure 4, is plotted in Figure 8 for DM DPI performed without (a) and with (b) the RC input filters in Figure 2. Notice that such a current does not include the DC current sunk by the IC for its operation, and no external load is connected to the cells. Figure 8 shows how such a DC current delivered by the battery pack in accordance with the DPI failure levels, (whose measured value without EMI is about $170 \mu \mathrm{A}$ ), can be significative of being affected by the injected disturbances if the RC filters are not included, reaching $6 \mathrm{~mA}$ for a $40 \mathrm{MHz}$ EMI injection frequency. It is interesting to observe that the measured DC current is negative (current delivered to the battery pack) for most EMI injection frequencies.
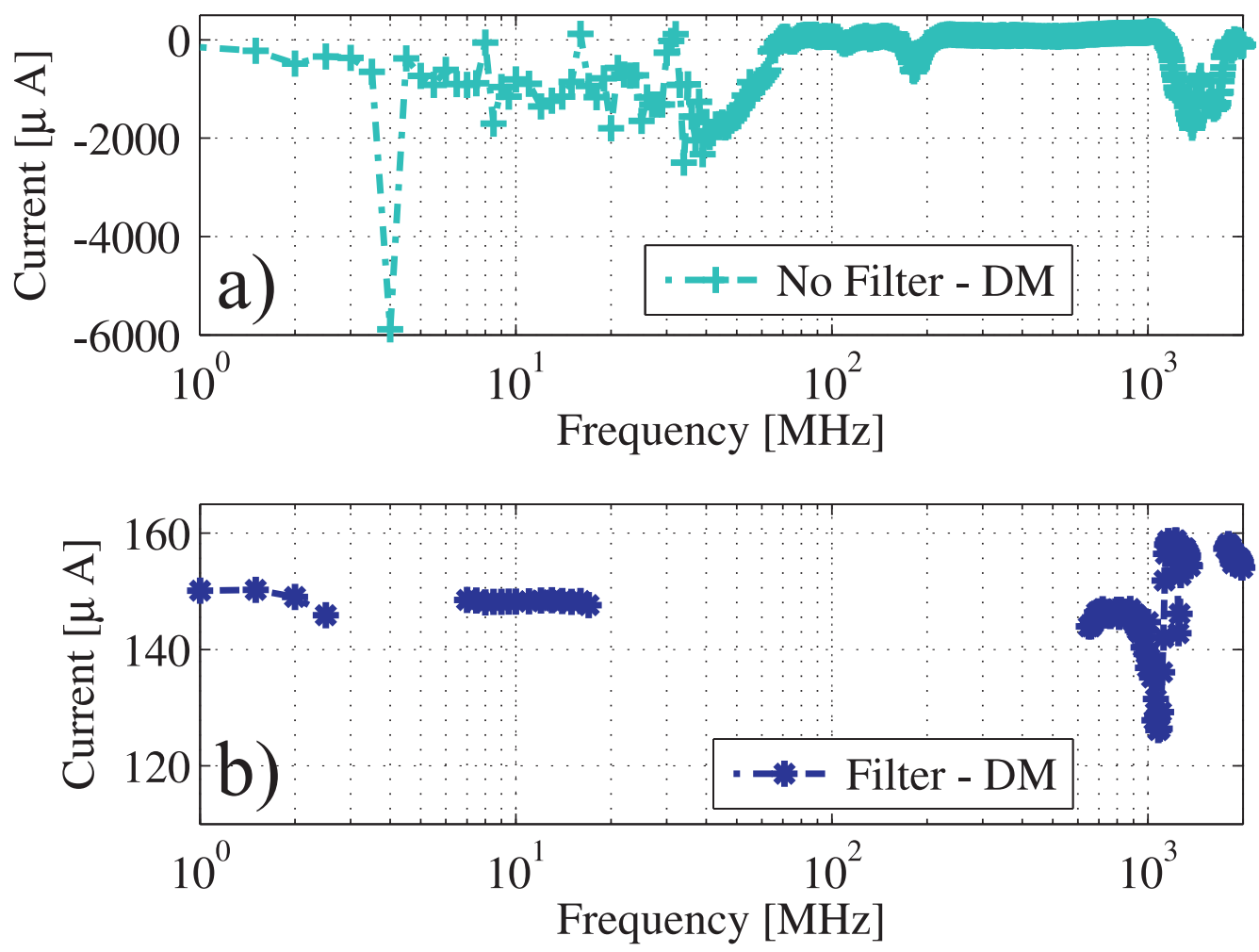

Figure 8. DC current absorbed from the battery pack by the BMS IC cell inputs in accordance with DPI failures levels in Figure 4 for DM injection performed on the 6th, without (a) and with (b) the RC filters.

\subsection{SPI Injection}

The immunity level of the DUT undergoing DPI on the SPI injection point in Figure 2 has also been investigated. Figure 9 reports measurement results for RF injections performed on the four SPI lines at the same time and injection performed on the SCK (serial clock) SPI line only. The respective total RF induced voltage at the same pins is reported in Figure 10. In the first case the four SPI injection capacitors to the signal terminal of the SMA connector in Figure 2 are all connected. In the latter case, only one injection capacitor between the signal terminal of the SMA connector in Figure 2 and the SCK pin of the IC is mounted on the PCB. 


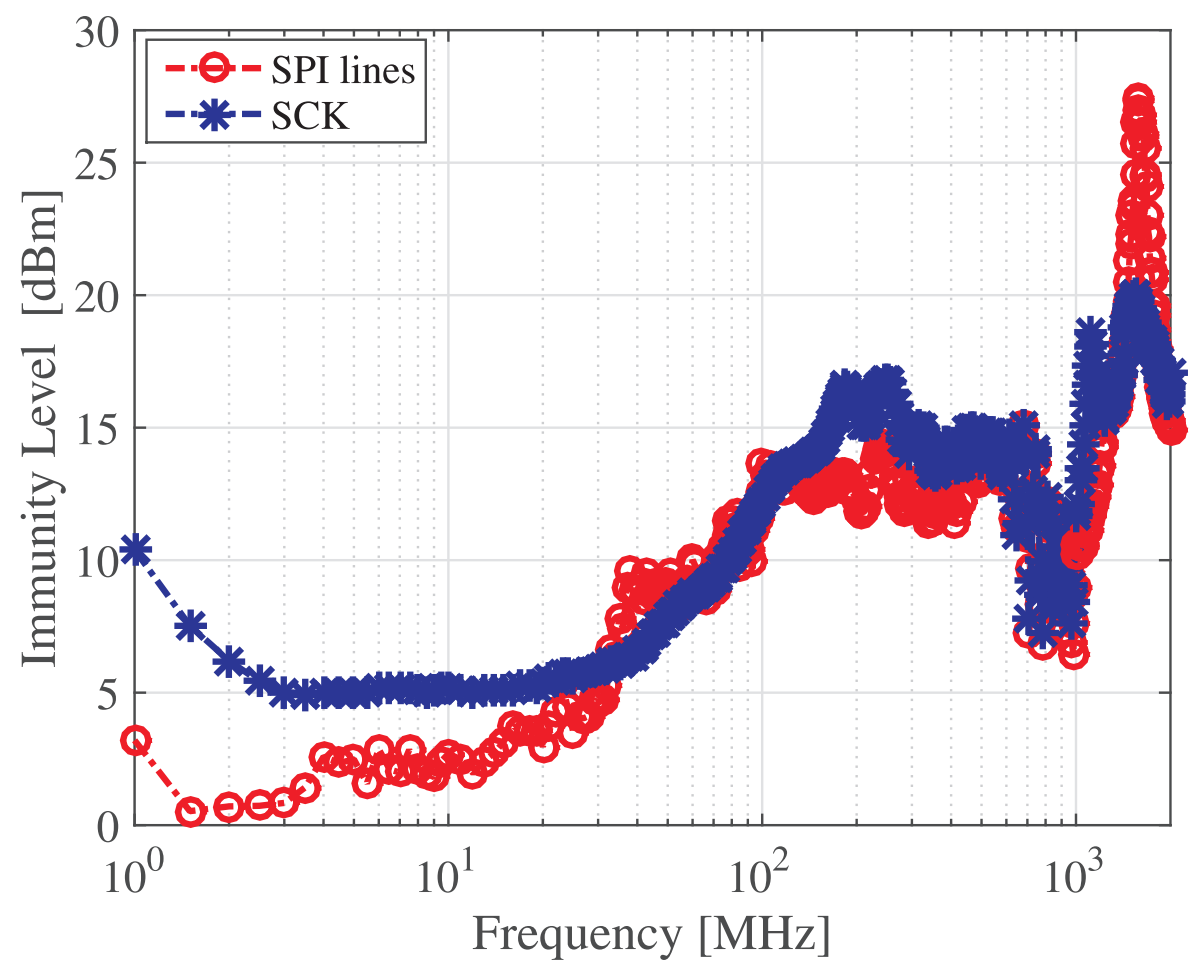

Figure 9. Measured immunity level for DPI on the SPI input pins: simultaneous injection on the four SPI lines and injection on the single SCLK line.

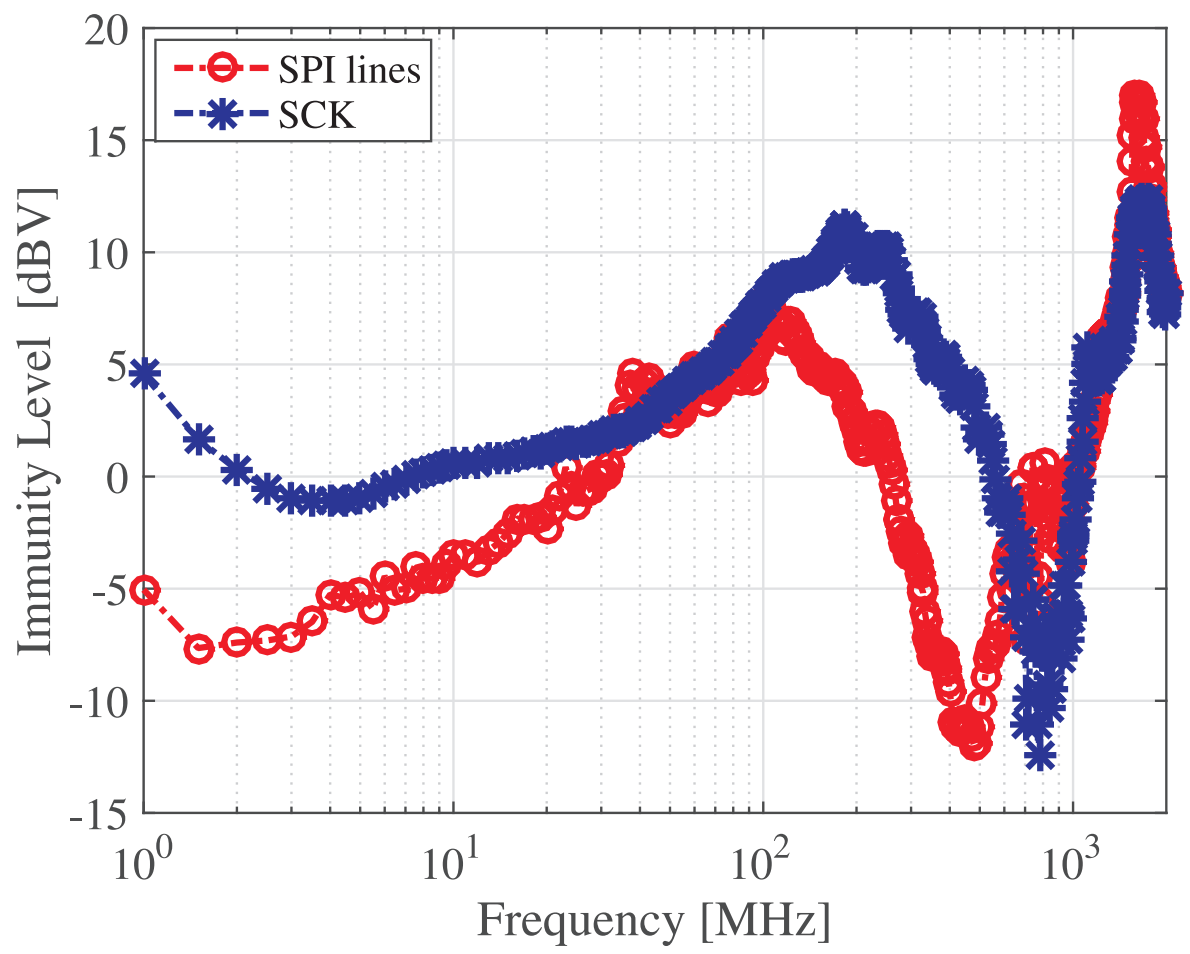

Figure 10. Total RF voltage induced at the SPI input pins: simultaneous injection on the four SPI lines and injection on the single SCLK line. 


\section{Failure Mechanisms}

By comparing the immunity level reported in Figure 9 for the SPI injection with the immunity level reported in Figure 4 for cell inputs injection, it can be highlighted that the immunity level for SPI injection is lower than the immunity level of the unfiltered cell inputs. This is a serious concern, since the EMI immunity for SPI injection cannot be improved by filtering [16] because EMI filters would give rise to an unacceptable degradation of nominal digital waveforms.

An analysis of the mechanisms giving rise to EMI-induced failures when DPI is performed on SPI lines has been carried out on the basis of the data retrieved during the DPI tests, in analogy to what was discussed in Section 4.1.2. Based on these data, failures below $100 \mathrm{MHz}$ are related, as one could expect, to errors in the SPI transmission detected by checking the PEC code. At higher frequency, however, EMI failures for SPI injection are related to an offset in the acquired cell voltages, equal for all the six cells, as shown in Figure 11. Such a behavior, which is similar to what was highlighted for DPI on the cell inputs in the high frequency range (Figure 6), can be related to EMI propagation inside the DUT to the internal ADC and/or to its reference voltage source.

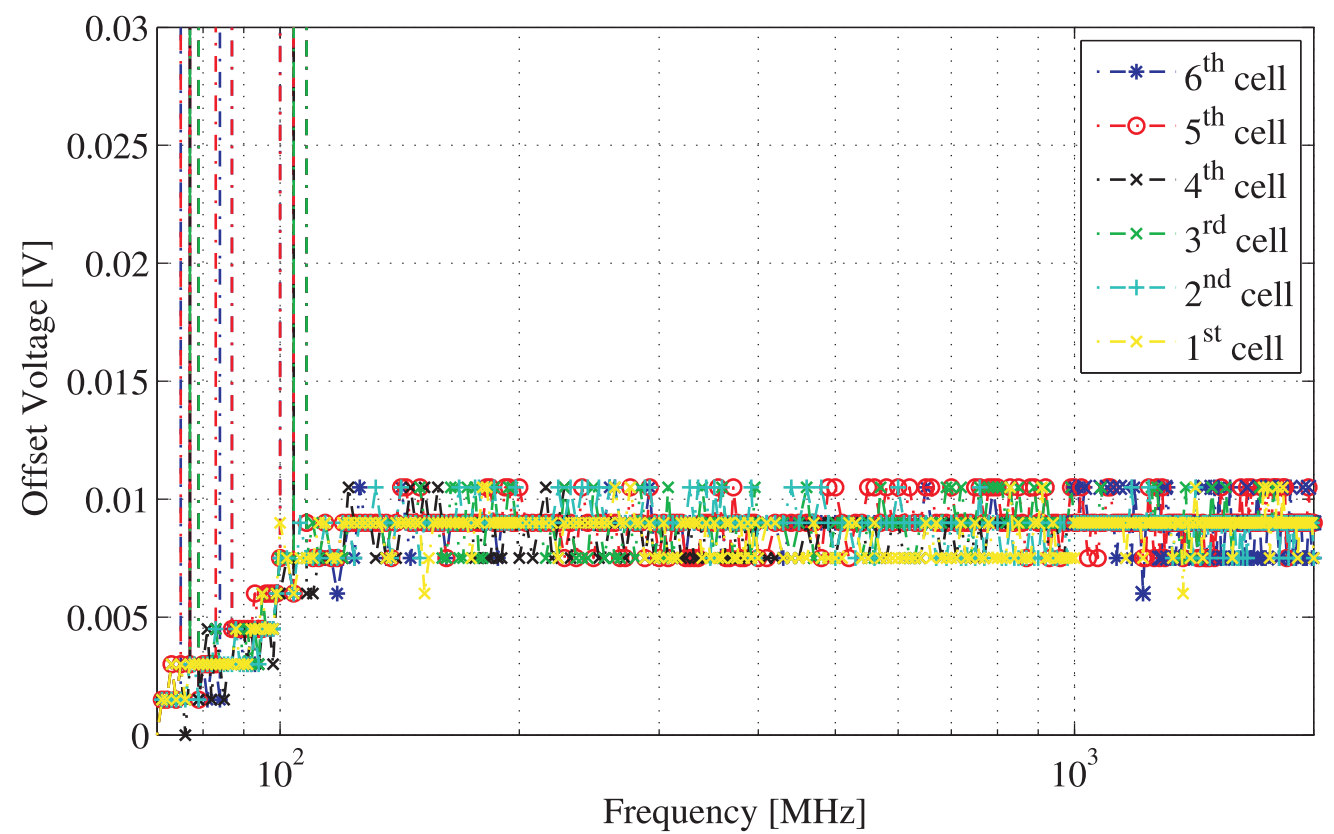

Figure 11. EMI-induced offset in the cell voltage readings obtained in accordance with failure levels of Figure 9 above $50 \mathrm{MHz}$ (simultaneous injection on the four SPI pins).

\section{Discussion: DPI Tests}

DPI measurements have been performed in the bandwidth $1 \mathrm{MHz}$ to $2 \mathrm{GHz}$ up to a maximum incident power of $37 \mathrm{dBm}$ on a commercial BMS. A test board has been specifically designed and fabricated in order to perform DPI in compliance with IEC 62132-4. In particular, DPI has been performed:

- On the cell monitoring inputs of the BMS IC connected to the top cell in the stack to be monitored (DM and CM injection), with and without RC low-pass filters recommended by the manufacturer;

- $\quad$ On the SPI lines.

During the tests, the following malfunctions in the operation of the BMS IC have been reported:

- Offset in the acquired cell voltages (considering that the target accuracy level of the IC an offset exceeding $10 \mathrm{mV}$ has been considered as a failure);

- $\quad$ SPI communication failures (PEC failure and/or communication impaired).

- An increase in the current absorption from the power supply. 
Offsets in acquired cell voltages have been reported both by DPI on the cell monitoring inputs and on the SPI communication lines. For what concerns cell monitoring input injection, an offset voltage has been reported for the cell undergoing injection, but also for other cells, depending on frequency. Communication failures have been reported for DPI in the communication lines only.

For what concerns DPI on cell monitoring inputs without the RC filters, a DPI immunity level from $5 \mathrm{dBm}$ to $15 \mathrm{dBm}$ has been reported up to $1 \mathrm{GHz}$. No substantial difference can be noticed for $\mathrm{CM}$ and DM injection. For what concerns DPI on cell monitoring inputs with the RC filters, a DPI immunity level exceeding the test level of $37 \mathrm{dBm}$ has been reported for most frequencies above $5 \mathrm{MHz}$. Nonetheless, an immunity level as low as $20 \mathrm{dBm}$ (for DM injection) has been reported in a frequency band around $700 \mathrm{MHz}$, in accordance with the parallel resonance of the filter capacitor (which is operating above its self-resonant frequency and shows an inductive impedance) and PCB parasitics. When filters were mounted, a slightly higher immunity level was measured for $\mathrm{CM}$ rather than for DM injection.

For what concerns DPI on SPI lines, a DPI immunity level lower than $5 \mathrm{dBm}$ has been measured both at low frequency ( $<30 \mathrm{MHz}$ ) and in the bandwidth $700 \mathrm{MHz}$ to $1 \mathrm{GHz}$. A slightly worse behavior has been reported for simultaneous injection on all the four SPI lines at the same time, rather than for injection performed on a single line. It is worth noting that unlike cells inputs, SPI communication lines cannot be filtered in order to avoid unacceptable degradation of the digital signal to be transmitted.

On the basis of the results of DPI tests, it can be observed that the immunity level of the BMS IC can be severely limited by its susceptibility to EMI superimposed onto the SPI line inputs.

\section{Radiated Susceptibility Tests}

In order to further investigate the BMS IC susceptibility, radiated EMI tests of a BMS IC have been performed in anechoic chamber in compliance with ISO11452-2 [26]. The DPI injection networks have been removed and the EMI filters on the cell inputs prescribed by the manufacturer have been included. The antenna has been placed both in front of the DUT and the cable harness. The DUT is located inside an anechoic chamber over a metal plane and it is remotely controlled and monitored by means of optical links. A sketch of the measurement setup is reported in Figure 12. The two terminals of the battery pack, monitored by the BMS, are connected through a $1.5 \mathrm{~m}$-long cable to two LISNs. According to [26], the operation of the DUT has been tested radiating the DUT with a $200 \mathrm{~V} / \mathrm{m}$ incident EM field, a typical test level for safety critical automotive applications, in the $200 \mathrm{MHz}-1.4$ $\mathrm{GHz}$ bandwidth, considering both horizontal and vertical polarization.

Figure 12 shows the radiated test setup with the antenna placed in front of the equipment under test (EUT corresponds to the PCB with the DUT and the battery pack). Referring to the this test setup, the EMI-induced wrong readings (area in gray) and the offset in the cell voltage readings in the anechoic chamber for vertical an horizontal polarizations are reported respectively in Figures 13 and 14. Both for vertical and horizontal polarization, the radiated field gives rise to completely wrong $\mathrm{ADC}$ readings, corresponding to the maximum or to the minimum values of the ADC range for a frequency lower than $400 \mathrm{MHz}$ in the gray area in both Figures 13 and 14). The same phenomena are also observed in the range $850-950 \mathrm{MHz}$ for horizontal polarization. Moreover, the results of radiated tests in Figures 13 and 14 highlight an EMI-induced offset in the acquired voltages in the range 650-900 MHz. 


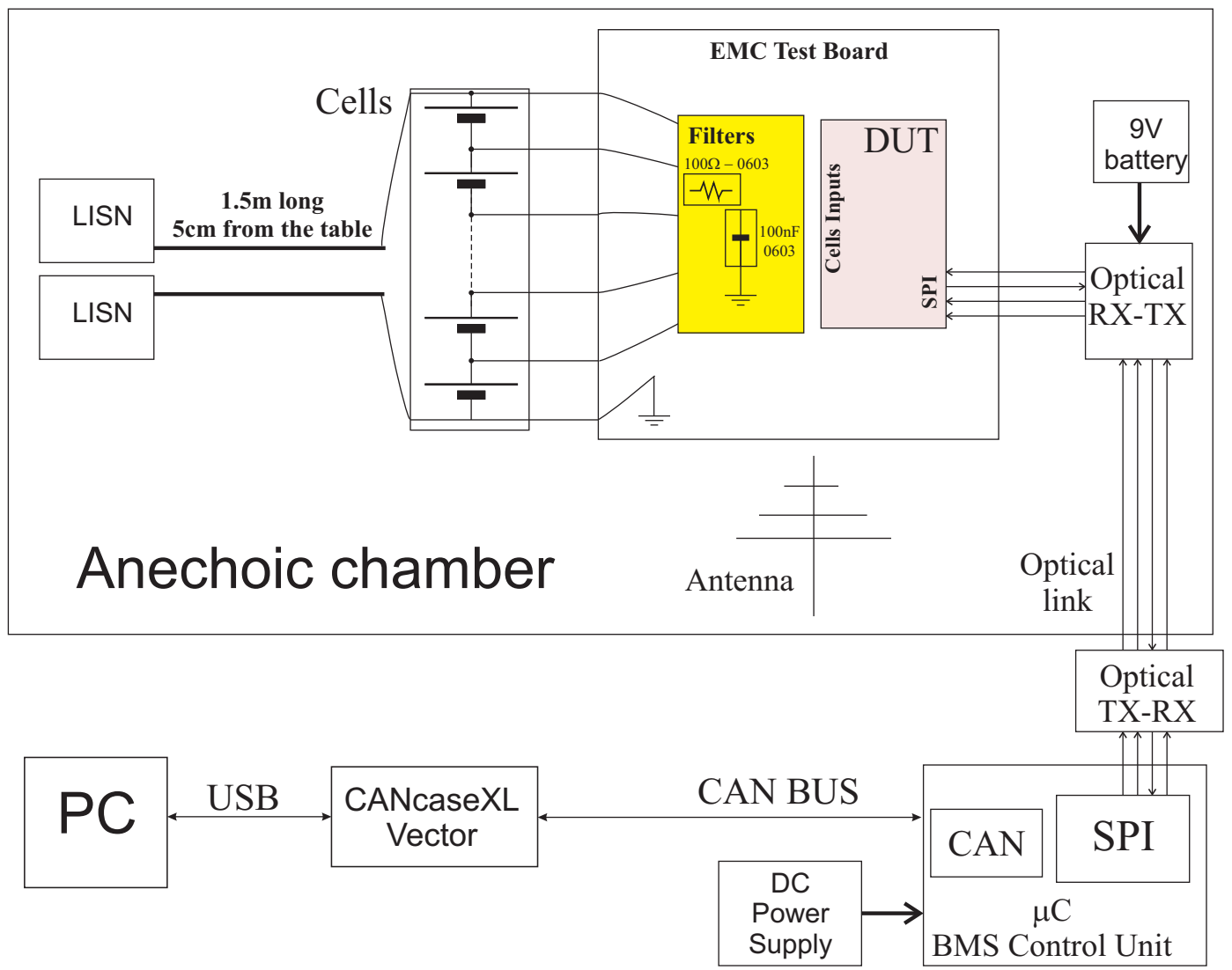

Figure 12. Radiated susceptibility test setup. Antenna in front of the equipment under test (EUT).

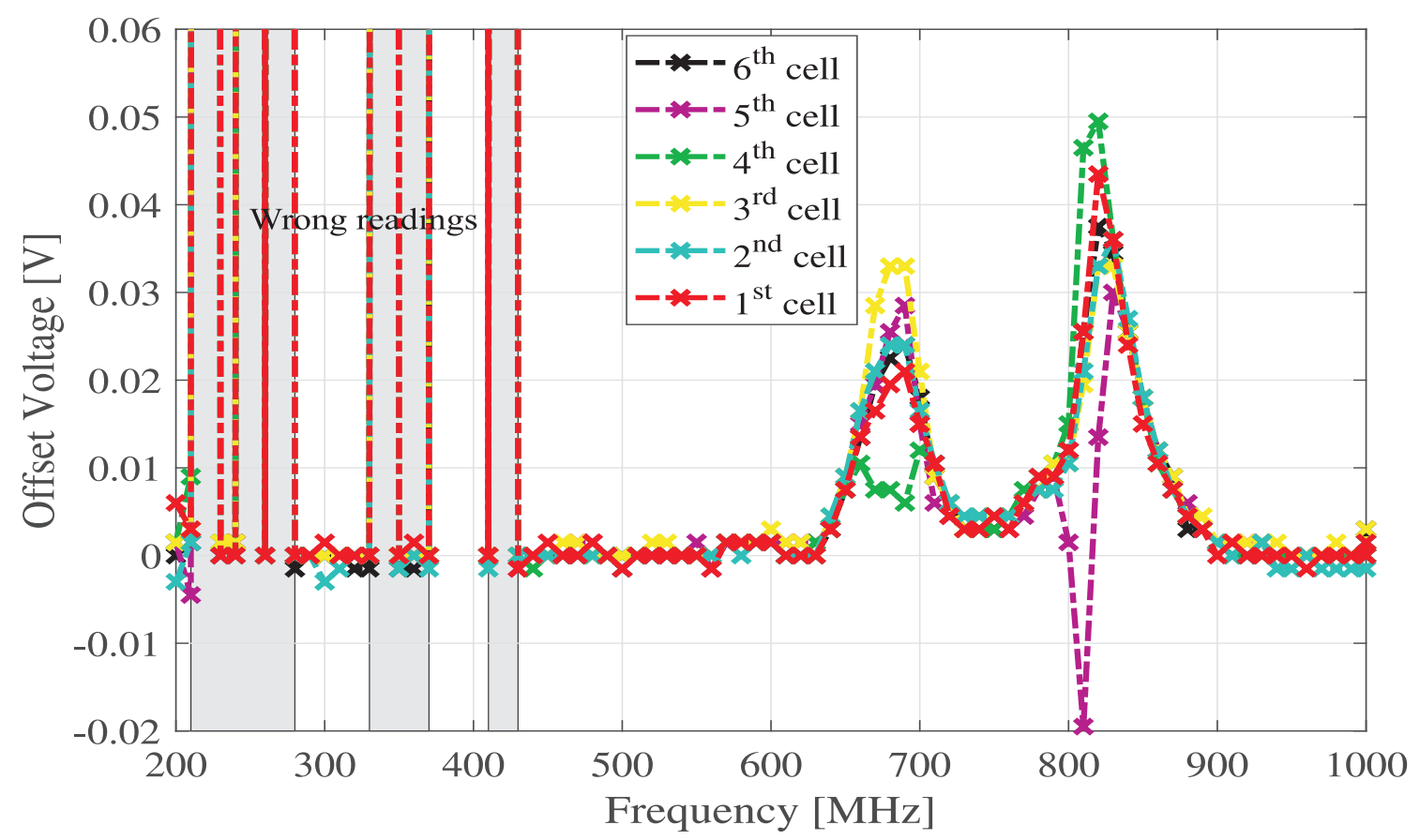

Figure 13. EMI-induced offset in the cell voltage readings. Antenna in front of the EUT (Figure 12). Vertical polarization. 


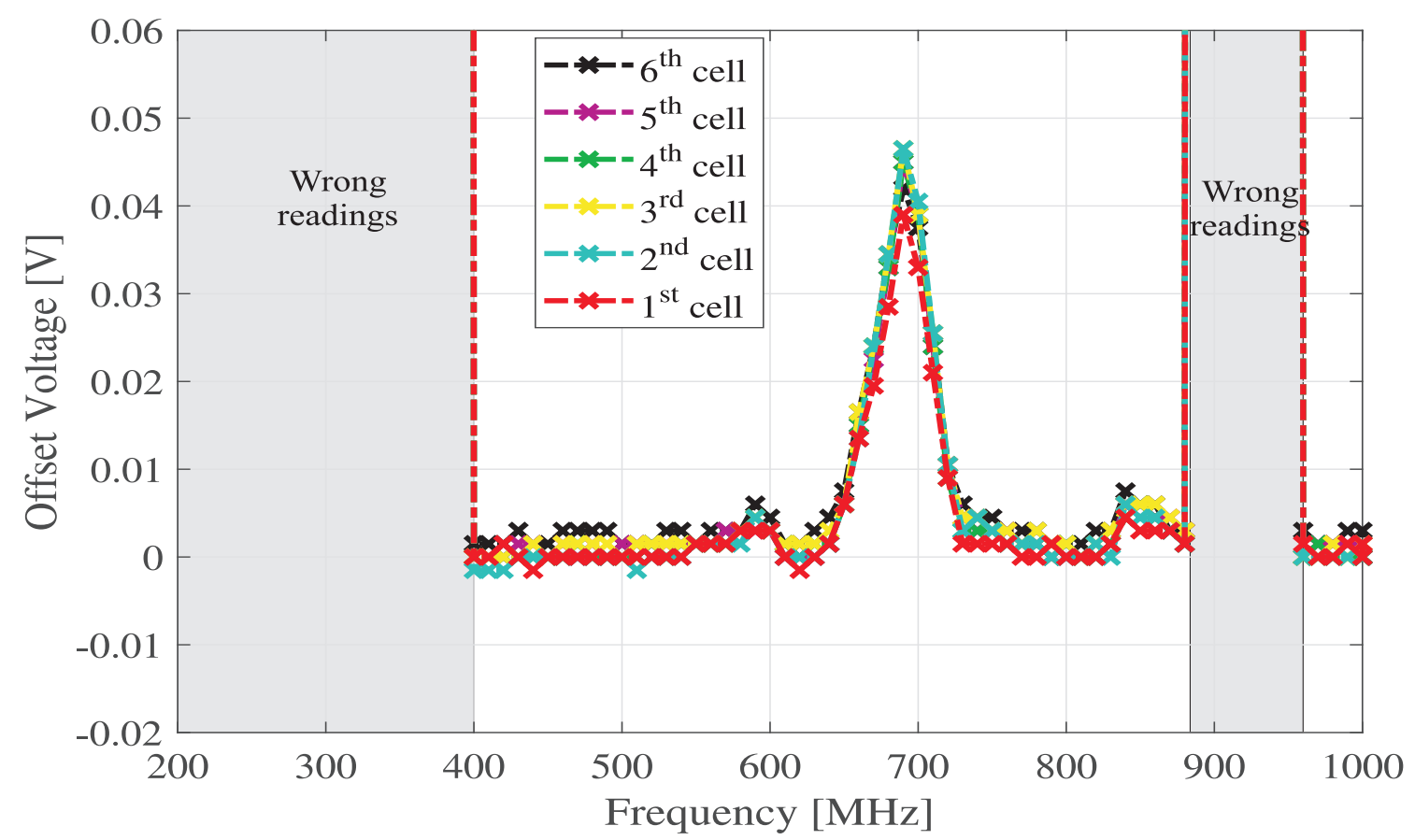

Figure 14. EMI-induced offset in the cell voltage readings. Antenna in front of the EUT (Figure 12). Horizontal polarization.

The same measurements have been repeated by moving the antenna in front of the cable, obtaining a similar phenomena. The respective wrong readings and EMI-induced offsets in the cell voltage readings in the anechoic chamber for vertical and horizontal polarizations are reported respectively in Figures 15 and 16.

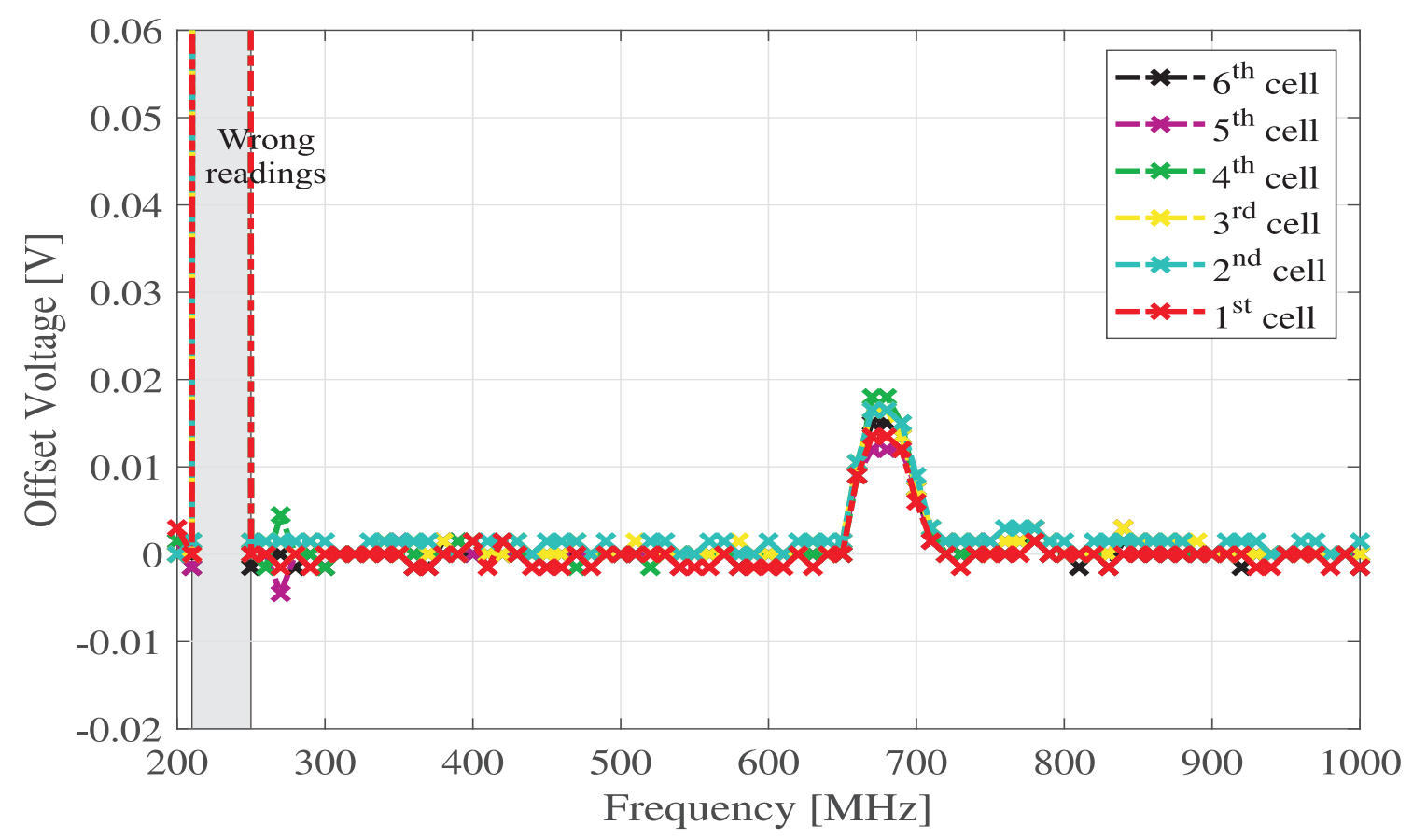

Figure 15. EMI-induced offset in the cell voltage readings. Antenna in front of the cable. Vertical polarization. 


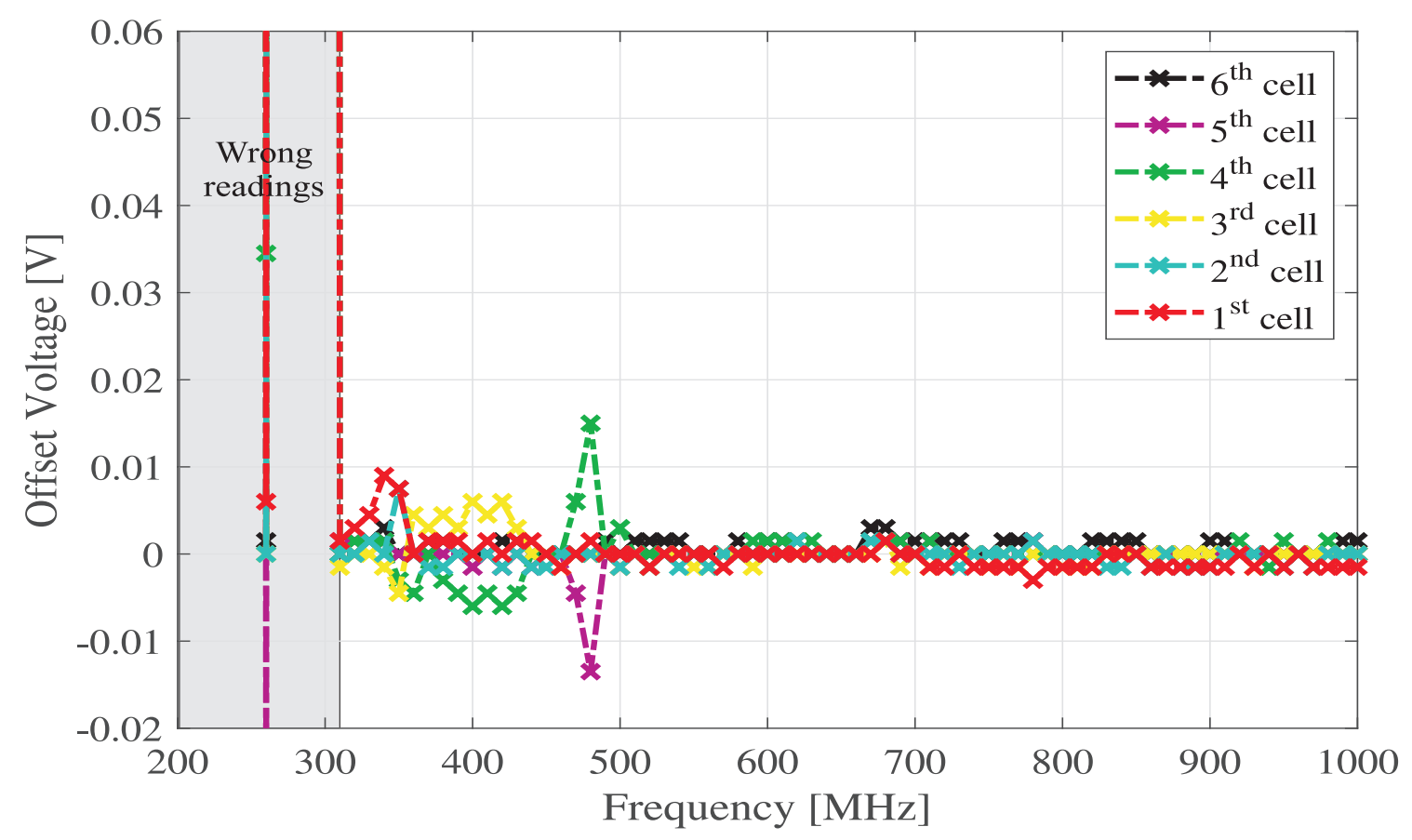

Figure 16. EMI-induced offset in the cell voltage readings. Antenna in front of the cable. Horizontal polarization.

\section{Discussion: DPI vs. Radiated Immunity Tests}

The radiated susceptibility measurements performed in compliance with ISO 11425-2 [26] aimed for establishing a correlation between the EMC performance of the BMS IC, previously assessed by the DPI method, and the susceptibility to EMI of a realistic BMS system IC. For a direct comparison, Figure 17 reports the immunity level measured by DPI tests on cell inputs (Figure 4)-its respective peak value in volts (from Figure 5) —and on the SPI lines (Figure 9); see Figure 17a-c respectively. Moreover, see the EMI-induced offsets in acquired cell voltages measured during radiated susceptibility tests in Figure $17 \mathrm{~d}, \mathrm{e}-$ for vertical and horizontal polarizations with the antenna placed in front of the EUT, respectively.

To obtain an approximate relation between DPI immunity level and radiated field strength, it has been observed that the failure threshold considered in DPI tests (EMI-induced offset in acquired cell voltages equal to $10 \mathrm{mV}$ ) has been reached irradiating the EUT in the bandwidth from 600 to $900 \mathrm{MHz}$ by a vertically polarized $\mathrm{E}$ field $E_{\mathrm{V}}=100 \mathrm{~V} / \mathrm{m}$, which approximately induces a CM voltage on the BMS PCB lines connected to the cell inputs with a peak amplitude

$$
V_{\mathrm{cm}}=\int_{0}^{h} E_{z}(z) \mathrm{d} z \simeq E_{\mathrm{v}} \cdot h=8.5 \mathrm{~V},
$$

where $h=8.5 \mathrm{~cm}$ is the height of the harness connecting the BMS to the cells with respect to the ground plane. The EMI amplitude estimated by (4) is consistent with the results of the DPI immunity test reported in $\mathrm{dBm}$ and in volts as EMI peak amplitudes, respectively, in Figure 17a,b. In fact, in the bandwidth around $700 \mathrm{MHz}$ where the effectiveness of $R C$ filters is impaired by the resonance highlighted in (1), the EMI immunity level both for CM and DM injections is similar to that defined in (4). 

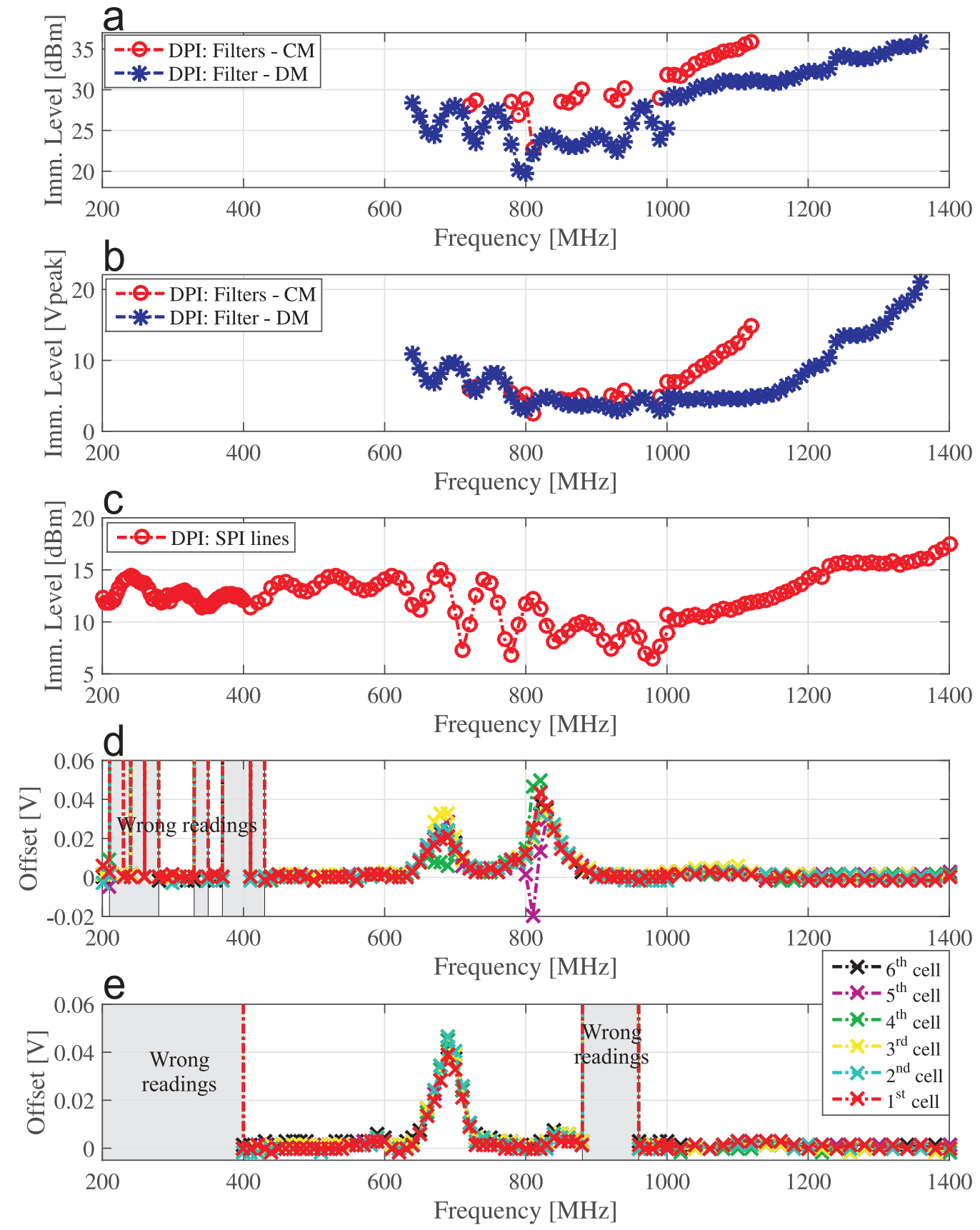

Figure 17. (a) Measured immunity level for DPI on the cell input pins: differential (DM) and common-mode (CM) injection, with $100 \Omega, 100 \mathrm{nF}$ RC filters in Figure 2, and (b) respective EMI peak amplitudes. (c) Measured immunity level for DPI on the four SPI lines. (d) EMI-induced offset in the acquired cell voltages, $\mathrm{E}=200 \mathrm{~V} / \mathrm{m}$. Vertical polarization. (e) EMI-induced offset in the acquired cell voltages, $\mathrm{E}=200 \mathrm{~V} / \mathrm{m}$, horizontal polarization.

Considering the significant differences of the injection mechanisms and of the test setup in DPI and radiated tests, further considerations on the correlation between IC-level DPI test results and system-level radiated immunity tests are difficult to be established and are also scarcely significant, since the results of radiated tests could be strongly influenced by the actual structure of the battery pack, including the BMS, which, in real applications, could be rather different with respect to the prototype considered in our investigation. Nonetheless, the same failure mechanisms (offset in acquired cell 
voltages and SPI communication failures) and the same critical EMI bandwidth highlighted during DPI tests have been found in system level tests.

In particular, an offset voltage of $10 \mathrm{mV}$, corresponding to the susceptibility level considered in DPI tests, has been observed by irradiating the system with an antenna placed in front of the EUT with a vertical polarization for a test frequency from $600-900 \mathrm{MHz}$. Considering that the board undergoing radiated tests includes the RC filters, such results are consistent with the results of DPI according to which the immunity of the EUT is particularly critical in the bandwidth around $700 \mathrm{MHz}$, where an immunity level of about $20 \mathrm{dBm}$ was reported.

\section{Conclusions}

The susceptibility to EMI of a BMS front-end IC for EVs and HEVs has been investigated in this paper by DPI tests performed according with IEC 62132-4. On the basis of the experimental results, it has been highlighted that the BMS IC under test can be significantly susceptible to EMI injected on its cell input terminals and on its digital communication (SPI) lines. For what concerns cell inputs injection, in particular, it has been observed that low pass RC filtering can be effective at improving the immunity to EMI of the DUT in the 10-600 MHz bandwidth, but its effectiveness is reduced above $600 \mathrm{MHz}$. On the other hand, the susceptibility to EMI applied on the SPI input lines, which cannot be filtered, is likely to be a major concern for the specific application. Finally, the different mechanisms giving rise to EMI induced failures of the specific DUT have been highlighted. Depending on the EMI frequency and on the injection points, an EMI-induced offset in the cell readings, SPI failures and completely wrong acquired values have been reported. An abnormal current absorbtion from the cells while performing DPI has also been observed.

The immunity to EMI of the same BMS system has been addressed even by radiated susceptibility measurements performed in compliance with ISO 11425-2 to establish a correlation between the EMC performance of the BMS IC, previously assessed by the DPI method, and the susceptibility to EMI of a realistic BMS system based on the same IC. During the radiated tests, which have been performed for a field strength of $200 \mathrm{~V} / \mathrm{m}$, the same failure mechanisms highlighted during DPI tests have been observed (offset in acquired cell voltages and SPI communication failures).

Funding: The lab activities have been supported by the Regione Piemonte within the Biomethair Project, Fondo Europeo P.O.R. 2007-2013.

Acknowledgments: The author thanks P. Crovetti and F. Fiori from Politecnico di Torino, Italy, who supported a preliminary conference paper [4], and Eng. G. Borio, M. Scaglione, and A. Bertino of the LACE, Torino, Italy, for setting up the test bench used for the radiated emission measurements.

Conflicts of Interest: The author declares no conflict of interest.

\section{References}

1. Richelli, A.; Colalongo, L.; Kovács-Vajna, Z.M. Analog ICs for Automotive under EMI Attack. In Proceedings of the 2019 AEIT International Annual Conference, Florence, Italy, 18-20 September 2019; pp. 1-6.

2. Aiello, O.; Fiori, F. On the Susceptibility of Embedded Thermal Shutdown Circuit to Radio Frequency Interference. IEEE Trans. EMC 2012, 54, 405-412. [CrossRef]

3. Aiello, O. Hall-Effect Current Sensors Susceptibility to EMI: Experimental Study. Electronics 2019, 8, 1310. [CrossRef]

4. Aiello, O.; Crovetti, P.S.; Fiori, F. Susceptibility to EMI of a Battery Management System IC for electric vehicles. In Proceedings of the 2015 IEEE International Symposium on Electromagnetic Compatibility (EMC), Dresden, Germany, 16-22 August 2015; pp. 749-754.

5. Aiello, O.; Fiori, F. A New MagFET-Based Integrated Current Sensor Highly Immune to EMI. Microelectron. Reliab. 2013, 53, 573-581. [CrossRef]

6. Aiello, O.; Fiori, F. A new mirroring circuit for power MOS current sensing highly immune to EMI. Sensors 2013, 13, 1856-1871. [CrossRef] [PubMed] 
7. Mutoh, N.; Nakanishi, M.; Kanesaki, M.; Nakashima, J. EMI noise control methods suitable for electric vehicle drive systems. IEEE Trans. Electromagn. Compat. 2005, 47, 930-937 [CrossRef]

8. Ansean, D.; García, V.M.; González, M.; Blanco-Viejo, C.; Viera, J.C.; Pulido, Y.F.; Sánchez, L. Lithium-Ion Battery Degradation Indicators Via Incremental Capacity Analysis. IEEE Trans. Ind. Appl. 2019, 55, 2991-3002. [CrossRef]

9. Omariba, Z.B.; Zhang, L.; Sun, D. Review on Health Management System for Lithium-Ion Batteries of Electric Vehicles. Electronics 2018, 7, 72. [CrossRef]

10. Lelie, M.; Braun, T.; Knips, M.; Nordmann, H.; Ringbeck, F.; Zappen, H.; Sauer, D.U. Battery Management System Hardware Concepts: An Overview. Appl. Sci. 2018, 8, 534. [CrossRef]

11. Chen, C.L.; Wang, D.S.; Li, J.J.; Wang, C.C. A Voltage Monitoring IC With HV Multiplexer and HV Transceiver for Battery Management Systems. IEEE Trans. VLSI 2015, 23, 244-253. [CrossRef]

12. Chol-Ho, K.; Moon-Young, K.; Gun-Woo, M. A Modularized Charge Equalizer Using a Battery Monitoring IC for Series-Connected Li-Ion Battery Strings in Electric Vehicles. IEEE Trans. Power Electron. 2013, 28, 3779-3787.

13. Cheng, K.W.E.; Divakar, B.P.; Wu, H.; Ding, K.; Ho, H.F. Battery-Management System (BMS) and SOC Development for Electrical Vehicles. IEEE Trans. Veh. Technol. 2011, 60, 76-88. [CrossRef]

14. Spadacini, G.; Pignari, S.A. Numerical Assessment of Radiated Susceptibility of Twisted-Wire Pairs With Random Nonuniform Twisting. IEEE Trans. EMC 2013, 55, 956-964. [CrossRef]

15. Richelli, A. EMI Susceptibility Issue in Analog Front-End for Sensor Applications. J. Sens. 2016, $2016,1082454$. [CrossRef]

16. Crovetti, P.; Fiori, F. IC digital input highly immune to EMI. In Proceedings of the 2013 International Conference on Electromagnetics in Advanced Applications (ICEAA), Torino, Italy, 9-13 September 2013; pp. 1500-1503.

17. Richelli, A.; Matiga, G.; Redoute, J.M. Design of a Folded Cascode Opamp with Increased Immunity to Conducted Electromagnetic Interference" in 0.18 um. Microelectron. Reliab. 2015, 55, 654-661. [CrossRef]

18. Richelli, A.; Delaini, G.; Grassi, M.; Redoute, J.M. Susceptibility of Operational Amplifiers to Conducted EMI Injected Through the Ground Plane into Their Output Terminal. IEEE Trans. Reliab. 2016, 65, 1369-1379. [CrossRef]

19. Andrea, D. Battery Management Systems for Large Lithium-Ion Battery Packs; Artech House Inc: Boston, MA, USA, 2010.

20. Jiang, J.; Zhang, C. Fundamentals and Applications of Lithium-Ion Batteries in Electric Drive Vehicles; John Wiley \& Sons Singapore Pte. Ltd.: Singapore, 2015.

21. Hauser, A.; Kuhn, R. 12-Cell balancing, battery state estimation, and safety aspects of battery management systems for electric vehicles. In Advances in Battery Technologies for Electric Vehicles; Scrosati, B., Garche, J., Tillmetz, W., Eds.; Woodhead Publishing: Cambridge, UK, 2015; pp. 283-326.

22. Lu, L.; Han, X.; Li, J.; Hua, J.; Ouyang, M. A review on the key issues for lithiumion battery management in electric vehicles. J. Power Sources 2013, 226, 272-288. [CrossRef]

23. Doughty, D.; Roth, P. A general discussion of Li-ion battery safety. Electrochem. Soc. Interface 2012, $21,37-44$.

24. IEC 623132-4:2006. Integrated Circuits, Measurement of Electromagnetic Immunity—Part 4: Direct RF Power Injection Method. Available online: https:/ / webstore.iec.ch/publication/ 6510 (accessed on 2 February 2020).

25. Generic IC EMC Test Specification, Ed. 2.1. 2017. Available online: http:/ / www.zvei.org/fileadmin/user upload/Presse_und_Medien/Publikationen/2017/Juli/Generic_IC_EMC_Test_Specification/Generic_ IC_EMC_Test_Specification_2.1_180713_ZVEI.pdf (accessed on 19 January 2020).

26. Road Vehicles-Vehicle Test Methods for Electrical Disturbances from Narrowband Radiated Electromagnetic Energy, ISO Std. 11451-2. 2005. Available online: https:/ /www.iso.org/standard/37999.html (accessed on 2 February 2020).

(C) 2020 by the authors. Licensee MDPI, Basel, Switzerland. This article is an open access article distributed under the terms and conditions of the Creative Commons Attribution (CC BY) license (http:/ / creativecommons.org/licenses/by/4.0/). 